\title{
Composite Materials for Next Generation Building Façade Systems
}

\author{
Q. Nguyen, T. Ngo, P. Mendis, P. Tran* \\ Department of Infrastructure Engineering, The University of Melbourne, Australia \\ ${ }^{*}$ Corresponding author: Phuong.tran@unimelb.edu
}

Copyright (C) 2013 Horizon Research Publishing All rights reserved.

\begin{abstract}
Composite materials, such as glass fibre reinforced polymers (GFRPs), possess the advantages of high strength and stiffness, low density, as well as manufacturing flexibility; therefore, their potential in replacing conventional materials (such as concrete, aluminium and steel) in building construction has become attractive. One of the major issues that hinder the extensive use of composite structures in high-rise building technology is related to their fire resistance performance. Significant efforts have been devoted to develop better material systems and composite manufacturing technologies to comply with various building construction safety codes, while maintaining the architectural aesthetic appeal. This paper presents the potential use of fibre reinforced polymer composites (FRPCs) in modern façade systems, with a special focus on their fire performance. A case study relating to the fire performance of glass fibre reinforced polymers is also presented. This case study is based on the numerical model established for glass fibre reinforced polyester, vinyl ester, epoxy and phenol without flame retardants.
\end{abstract}

Keywords Fire Performance, Composite Materials, Glass Fibre Reinforced Polymer, Fire Safety, Building Construction

\section{Introduction}

Fibre reinforced polymer composites (FRPCs) were first discovered in the 1940s following the rapid development of the petrochemical manufacturing industry. The combination of the two components in the composites, i.e. the reinforcing phase and the continuous phase, offers superior properties in comparison with individual components. The continuous phase (or the matrix) helps keep the fibres in their intended positions, protecting them from environmental impact, transferring loads to the fibres, as well as providing additional strength. Fibres, on the other hand, ensure the strength and stiffness of the composite. With the advantages of high strength and stiffness, low density, and highly flexible shaping, composites become potential candidates to replace conventional materials (such as aluminium and steel) in civil applications [1]. For example, carbon fibre reinforced polymer composites contribute to a 50-70\% weight reduction as an alternative to conventional metal-based materials [2]. In addition, the manufacturing flexibility of FRPC products is well-suited with the demands of architects and engineers in designing complex building structures such as the façade systems while maintaining mechanical properties and durability.

However, early applications of FRPCs were related mostly to the high performance products used in the aerospace, defence and automobile industries due to the high manufacturing cost. The applications of FRPCs have been then extended to other civil industries through many research and development projects conducted since the early 1990s. The market share distribution of FRPCs for construction has been raised to more than $25 \%$ and it has become the second largest field of FRPC application (Figure 1). FRPCs are used in construction as structural components, and internal or external reinforcements for concrete structures. Besides the strengthening and rehabilitation effects of FRPCs for concrete structures [3-13], FRPC itself structurally outperforms conventional construction materials such as concrete and steel. Concrete and steel bridges require $5 \%$ of their original materials to be replaced after 50 years, whereas no maintenance is required for bridges made from glass fibre reinforced polymers (GFRPs) [2].

For these reasons, the potential of FRPCs as an innovative material in modern façade systems has captured significant interest in recent years. Compared to other applications in construction, FRPCs are highly competitive in façade systems because of their light weight, flexibility, and cost effectiveness in the manufacturing process. FRPCs make it possible to design complex façade systems with low embodied energy (as illustrated in Table 1), thus they have drawn substantial attention from façade designers worldwide. Nevertheless, there are many types of FRPCs with varying properties and manufacturing costs, resulting in some difficulty in selecting the suitable material system for the façade elements. Additionally, one of the key drawbacks of FRPCs is their relatively low fire resistance, which still requires comprehensive investigations in order to be applied 
in façade systems subjected to strict fire safety codes. To address these concerns, this paper will explores the potential applications of FRPCs in modern façade systems, with a special focus on their fire performance. A case study of the fire performance of glass fibre reinforced polymers will be presented. This case study is conducted numerically on a fire dynamic model established for glass fibre reinforced polyester, vinyl ester, epoxy and phenol composites without flame retardants.
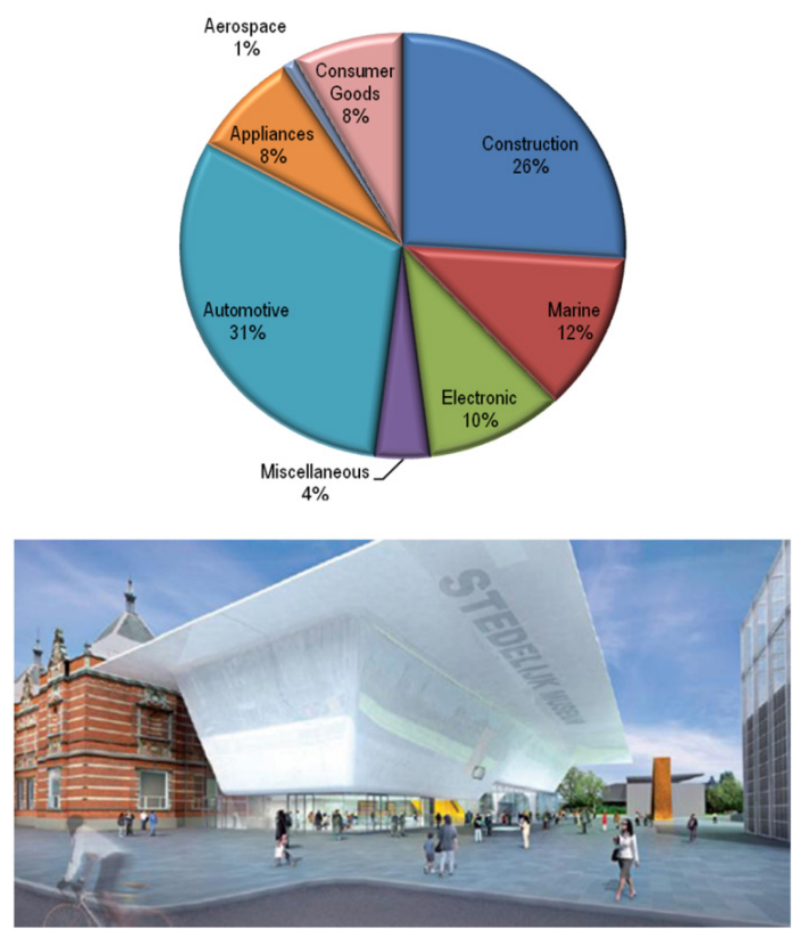

Figure 1. (a) Market share distributions of FRPCs [2]; (b) city museum with FRPC façade in the Netherlands

\section{Overview of Façade Systems}

The advantages and potential of using FRPCs in modern façade systems as alternative materials to metal-based ones has attracted considerable interest, including investigations on the various types of FRPCs with varying thermo-mechanical properties, environmental impacts, life cycles and manufacturing processes. A thorough understanding on each type is necessary in order to choose suitable materials to meet the design demands, and the structural and safety requirements. The choices for matrix and fibre reinforcement constituents of FRPCs, as well as the methods to combine them will both affect the properties of the composites. Figure 2 gives an outline of the potential types of FRPCs for façade applications.

One of the most important parameters for selecting FRPCs is the limiting matrix glass transition temperature $(T g)$ and the maximum serving temperature (Tser) of the composite, as given in Equation 1 [2]:

$$
T s e r \leq T g-28^{0} \mathrm{C}
$$

Resins with a higher value of $T g$, however, possess higher brittleness and therefore require higher curing temperatures, longer curing times, and consequently lead to higher costs. Moisture absorption, fire rating, possibility of micro-cracking at the conjunction surface between the fibres and the matrix, as well as environmental impact need to be taken into consideration.

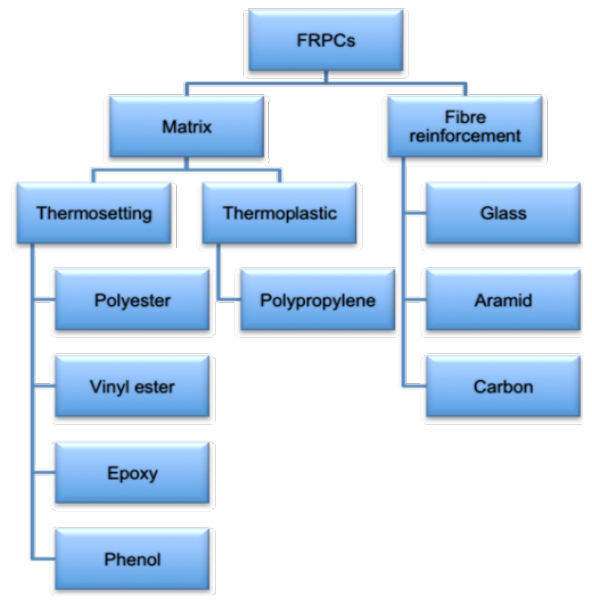

Figure 2. Classification of different types of FRPC for façade applications

Table 1 provides a comparison of the properties of polyester, epoxy and phenol, which are all thermoset resins. Polypropylene, which has embodied the characteristics of thermoplastics with poor solvent-resistance, is not discussed in this work. Polypropylene phenol is proven to be the best among the three types as it has excellent fire and chemical performance, good structural behaviour, and suitable transition temperature. Nevertheless, the fabrication of phenol is comparatively complex; therefore, it is especially used as the resin in advanced performance composite materials in construction rather than for façade systems. Similar to phenol, epoxy also possesses better properties in terms of structural, chemical and fire performance, as well as moisture resistance in comparison with polyester. Polyester is, on the other hand, more eco-friendly than epoxy when considering their impacts on the environment through three parameters: cumulative energy demand, greenhouse gas emissions and eco-points. Cumulative energy demand indicates the fossil fuel consumption, which plays an important role in the environmental impact. Greenhouse gas emissions reflect the influence with regard to the issue of climate change, and eco-points show the aggregate environmental impact, which is evaluated according to the ReCiPe impact assessment method [2]. Besides having better environmental influences as indicated by a lower ReCiPe, cumulative energy demand and greenhouse gas emission values (as presented in Table 1), polyester is often more convenient in the fabrication process compared with epoxy. This is based on the fact that the gel time of polyester is normally longer than epoxy and, therefore, it could be well-controlled and flexibly tailored compared to quick hardening epoxy. Furthermore, the curing process of epoxy is different from unsaturated polyester as epoxy is required to be cured at elevated temperatures. 
Table 1. Comparison of resins [2, 14]

\begin{tabular}{cccc}
\hline Properties & Polyester & Epoxy & Phenol \\
Curing method & Addition-curing system & Addition-curing system & Condensation reaction \\
Structural performance & Fair & Good & Good but brittle \\
Corrosion and chemical resistance & Poor & Good & Excellent \\
Moisture absorption & Poor & Fair to Good & Excellent \\
$\mathrm{T}_{\mathrm{g}}\left({ }^{\circ} \mathrm{C}\right)$ & 71 & $93-177$ & $71-121+$ with post cure \\
Fire, smoke and toxicity & $\mathrm{n} / \mathrm{a}$ & Requires additives & Excellent \\
Cumulative energy demand $(\mathrm{MJ} / \mathrm{kg})$ & $62.8-78$ & $76-137$ & $\mathrm{n} / \mathrm{a}$ \\
Greenhouse gas emissions $\left(\mathrm{kg} \mathrm{of} \mathrm{CO}_{2} \mathrm{e} / \mathrm{kg}\right)$ & 2.3 & $4.7-8.1$ & $\mathrm{n} / \mathrm{a}$
\end{tabular}

One of the issues is that most thermoset resins absorb moisture from the surroundings and deteriorate from the time they get exposed to the environment (Figure 3). However, this issue could be tackled by using a gel-coat covering the surface of the thermoset composites. The gel-coat also provides a smooth and uniform appearance for the composite façade. The current pressing issue that prevents the application of FRPCs in façade systems lies in their fire performance. While many recent studies in literature focus on the thermo-mechanical responses of composites subjected to fire, which may eventually lead to the collapse of buildings and structures, the most lethal and quickest impacts on occupants during a fire event are heat and smoke production.

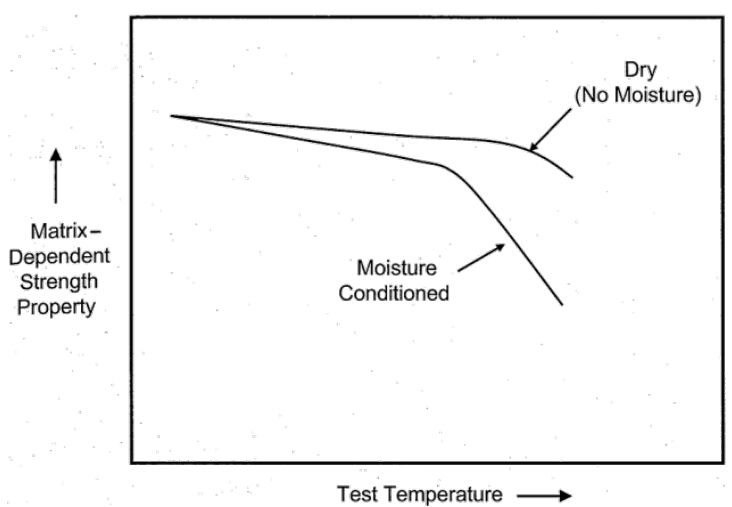

Figure 3. Moisture absorption influence on matrix strength properties [14]

\section{A Case Study on Fire Performance of Gfrps}

Fire performance of FRPC is investigated using the single burning item (SBI) test complying with fire safety code EN13823:2010 [15], which is a part of the Eurocode for fire ratings of building products. The specimen is tested vertically with a propane gas burner positioned at the corner of two perpendicular walls of the sample (Figure 4). The output results from the SBI test are the total heat released from the specimen in the first $600 \mathrm{~s}\left(\mathrm{THR}_{600 \mathrm{~s}}\right)$ after exposure to the main burner, the maximum quotient of heat release rate from the specimen (FIGRA $0.2 \mathrm{MJ}$ ) and the time of its exposure to the main burner when the threshold value of THR exceeds $0.2 \mathrm{MJ}$, and the total smoke production rate $\operatorname{SPR}(\mathrm{t})$ of the specimen. A backing board is located $80 \mathrm{~mm}$ from the back of the wings and is made from calcium silicate. The dimensions of the backing board a570 $\mathrm{mm} \times 1500 \mathrm{~mm} \times$ $12 \mathrm{~mm}$ (length $\mathrm{x}$ height $\mathrm{x}$ width) at the back of the short wing, and $1080 \mathrm{~mm}$ x $1500 \mathrm{~mm}$ x $12 \mathrm{~mm}$ (length $\mathrm{x}$ height $\mathrm{x}$ width) at the back of the long wing.

EN13501-1:2007 [16] also classifies the materials that can be used in building construction. According to this Eurocode, materials in buildings must meet the requirements of class B-s2-d0 category. This class B satisfaction requires a number of criteria to be met, including that no lateral flame is to spread over the edge of the specimen, the fire growth rate index (FIGRA) measured at the total heat release threshold of $0.2 \mathrm{MJ}$ does not exceed $120 \mathrm{~W} / \mathrm{s}$, and the total heat release of the first 600 seconds after the combustion ignition (around the $300^{\text {th }}$ second) does not exceed 7.5 MJ. The requirements for class $\mathrm{s} 2$ include that the smoke growth rate is less than $180 \mathrm{~m}^{2} / \mathrm{s}^{2}$, and the total smoke production of the first $600 \mathrm{~s}$ after the combustion ignition does not exceed $200 \mathrm{~m}^{2}$. Class $\mathrm{d} 0$ also requires no burning/melting droplets in the $600 \mathrm{~s}$ duration of the SBI test. 

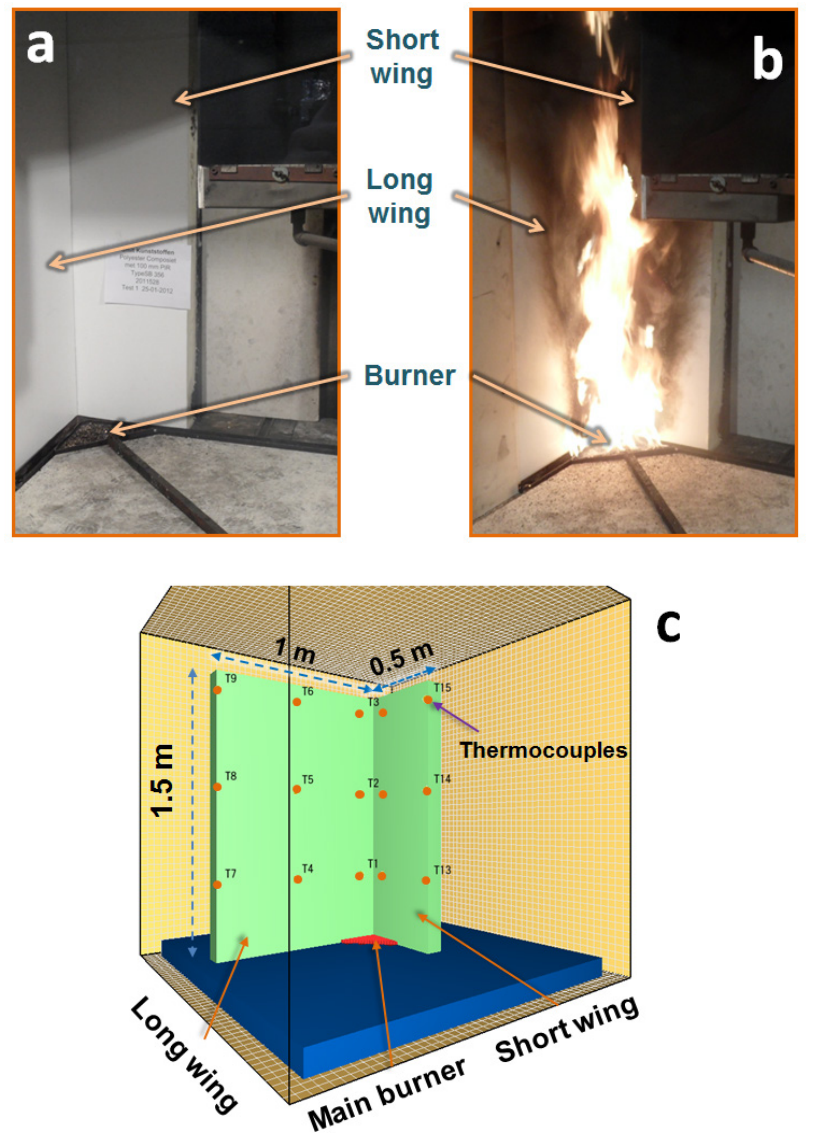

Figure 4. (a) Typical single burning item test setup, and (b) testing of GFRP composite panels. (c) Numerical model for SBI test showing dimensions of the composite sandwich. Thermocouples could be placed at various points on the front surface of the sample to monitor the temperatures during the burning process.

A case study is carried out on this work to investigate the total heat release and fire growth rate of GFRP. Glass fibres with low cost, high strength and chemical resistance are chosen as they are compatible for façade systems. Polyester, vinyl ester, epoxy and phenol based GFRPs are quantified and compared. The computational fluid dynamics (CFD) analysis is based on Fire Dynamic Simulator (FDS) (version 5.5.3) and is visualised by Smokeview (version 5.6), which were developed by the National Institute of Standards and Technology USA (NIST). In this research, the production of hot gas from the pyrolysis process of FRPC and the spread of the flame in the SBI test are conveniently simulated using FDS. Computational time is set to 900 seconds and the ignition time is set at the $300^{\text {th }}$ second. The CFD mesh size is discretised uniformly in all directions with a cubic element of size $40 \times 40 \times 40 \mathrm{~mm}$ for the entire test room with $3 \times 3 \mathrm{~m}^{2}$ area and $2.4 \mathrm{~m}$ height. The specimen is $1.5 \mathrm{~m}$ high and 200a mm thick, and the lengths of the long and short wings is $1.0 \mathrm{~m}$ and $0.5 \mathrm{~m}$, respectively. The sample is placed in the test room so that each wing is parallel and $0.7 \mathrm{~m}$ away from the walls. The burner is positioned right at the corner of the specimen and the burning plane is $80 \mathrm{~mm}$ above the ground. The burner frame is made of steel. The wings are designed as multilayer panels with $12 \mathrm{~mm}$ of calcium silicate and $200 \mathrm{~mm}$ of composite material. Commercial propane gas is used as the fuel for the burner, and the associated parameters for the propane burner are presented in Table 2. Other required parameters for setting up the numerical model are SOOT_YIED and IDEAL values that indicate the fraction of fuel converted into smoke particulate, which is strongly related to the smoke production of liquid fuel in fire. For propane, the default value of SOOT_YIELD is 0.01 . IDEAL is a logical input of the fuel, which indicates the completion of fuel burning. It is assumed in this study that all propane is burnt completely and IDEAL is set to be FALSE. According to EN13823:2010, the heat released from the burner should be equal to $30 \mathrm{~kW}$, which corresponds to a heat release rate per unit area (HRRPUA) of $960 \mathrm{~kW} / \mathrm{m}^{2}$ set for the burner in this study.

Materials in this numerical model include stainless steel for the burner, gypsum board for the walls of the test room, resins (polyester, vinyl ester, epoxy and phenol), glass fibre for the composite panel, and calcium silicate for the backing/gypsum board. All the materials are heat exchangers except for the polymeric resins and calcium silicate. Calcium silicate and the polymeric resins are materials that have exothermal pyrolysis reactions when subjected to fire. The pyrolysis model of solid subjects is calculated according to Equation 2:

$$
r=\frac{\partial}{\partial t}\left(\frac{\rho}{\rho_{0}}\right)=\left(\frac{\rho}{\rho_{0}}\right)^{n} A \mathrm{e}^{\left(-\frac{E}{R T}\right)},
$$

where $r$ is the reaction rate, $\rho$ is the density, $\rho_{0}$ is the initial density, $A$ is the pre-exponential factor, $E$ is the activation energy, $R$ is the Stefan-Boltzmann constant, $T$ is the temperature of the material, and $n$ is the reaction order. The values of $A$ and $E$ could be calculated by FDS or prescribed by the users. In this model, the pre-exponential factor $A$ and the activation energy of the calcium silicate (backing board) are determined from thermal differential analysis (TGA) [17-19]. The values $A$ and $E$ of the resins are calculated by FDS based on the reference temperature of mass loss (Equation 3 and Equation 4). This reference temperature of mass loss, which is the temperature at which $5 \%$ of the weight of the sample is lost, is determined from TGA. It should also be noted that the evaporation of water from the sample is not considered as a part of this $5 \%$ mass loss.

$$
\begin{aligned}
& E=\frac{e r_{p}}{Y_{0}} \frac{R T_{p}^{2}}{\dot{T}}, \\
& A=\frac{e r_{p}}{Y_{0}} e^{E / R T_{p}} .
\end{aligned}
$$

Here, $T_{p}$ is the reference temperature, and $r_{p} / Y_{0}$ is the reference rate for a single component where the reference rate is equal to the reaction rate at the reference temperature. $\dot{T}$ is the heating rate, which is the rate at which temperature increases in the TGA test. The default value for the heating 
rate in the TGA test is $5 \mathrm{~K} / \mathrm{min}$.

Two important characteristic parameters of the pyrolysis materials are the heat of reaction and heat of combustion. The heat of reaction $(\mathrm{kJ} / \mathrm{kg})$ is the heat required for materials to react as a solid fuel. In other words, this value expresses the external energy supplied to each kilogram of the material to ignite the combustion. The heat of reaction of a solid material $(\mathrm{kJ} / \mathrm{kg})$ is equal to the difference between the enthalpy of its solid and gas state [17]. On the other hand, the heat of combustion is the heat that each kilogram of the material releases in the burning reaction. This parameter is important for the fire dynamic simulation because it helps to accurately calculate the amount of heat released. In this model, the heat release source is from the burner and the gas reaction of unsaturated polyester and calcium silicate.

Input data for the polyester, epoxy, vinyl ester, phenol and the backing board is given in Table 2 and Table 3. The properties of calcium silicate are chosen from the requirements of EN13823:2010 for calcium silicate. The specific heat and thermal conductivity of calcium silicate varies with temperature and is introduced into FDS in the form of a RAMP function.

Table 2. FDS material parameters used in the simulation for polyester, epoxy, vinyl ester and phenol

\begin{tabular}{|c|c|c|}
\hline Parameter & Unit & Value \\
\hline \multicolumn{3}{|l|}{ Polyester [17] } \\
\hline Specific heat & $\mathrm{kJ} / \mathrm{kg} \cdot \mathrm{K}$ & 2.03 \\
\hline Density & $\mathrm{kg} / \mathrm{m}^{3}$ & 1070 \\
\hline Heat of combustion & $\mathrm{kJ} / \mathrm{kg}$ & $1.13 \mathrm{E}+06$ \\
\hline Reference temperature of $5 \%$ mass loss & ${ }^{\circ} \mathrm{C}$ & 274 \\
\hline Heat of reaction & $\mathrm{kJ} / \mathrm{kg}$ & $1.55 \mathrm{E}+04$ \\
\hline Emissivity & - & 0.9 \\
\hline $\mathrm{Nu}$ fuel* & $\mathrm{kg} / \mathrm{kg}$ & 0.88 \\
\hline \multicolumn{3}{|l|}{ Vinyl ester [20] } \\
\hline Specific heat & $\mathrm{kJ} / \mathrm{kg} \cdot \mathrm{K}$ & \\
\hline Density & $\mathrm{kg} / \mathrm{m}^{3}$ & \\
\hline Heat of combustion & $\mathrm{kJ} / \mathrm{kg}$ & $1.08 \mathrm{E}+06$ \\
\hline Reference temperature of $5 \%$ mass loss & ${ }^{\circ} \mathrm{C}$ & 360 \\
\hline Emissivity & - & 0.9 \\
\hline \multicolumn{3}{|l|}{ Epoxy [21] } \\
\hline Specific heat & $\mathrm{kJ} / \mathrm{kg} \cdot \mathrm{K}$ & 1.54 \\
\hline Density & $\mathrm{kg} / \mathrm{m}^{3}$ & 1380 \\
\hline Heat of combustion & $\mathrm{kJ} / \mathrm{kg}$ & $1.08 \mathrm{E}+06$ \\
\hline Reference temperature of $5 \%$ mass loss & ${ }^{\circ} \mathrm{C}$ & 385 \\
\hline Heat of reaction & $\mathrm{kJ} / \mathrm{kg}$ & 198 \\
\hline Emissivity & - & 0.9 \\
\hline
\end{tabular}

\section{Phenol [22]}

Specific heat

$\mathrm{kJ} / \mathrm{kg} . \mathrm{K}$

Density

$\mathrm{kg} / \mathrm{m}^{3}$

Heat of combustion

$\mathrm{kJ} / \mathrm{kg}$

$1.08 \mathrm{E}+06$

Reference temperature of $5 \%$ mass loss

${ }^{\circ} \mathrm{C}$ 
Table 3. Material parameters used for the calcium silicate backing board [17, 18]

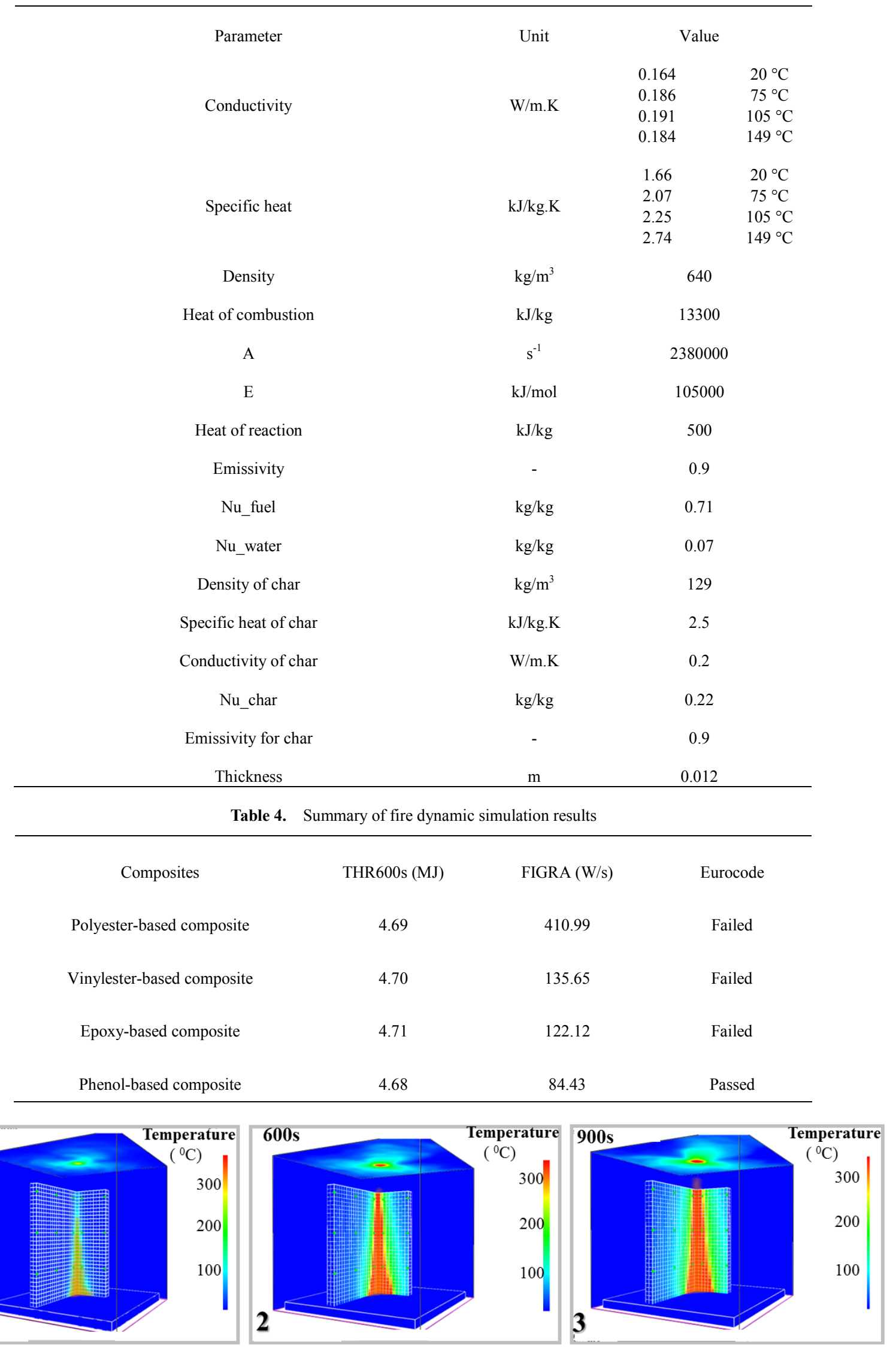

Figure 5. Snapshots of the simulated burning process of the SBI test at different times 
The numerical results summarised in Table 4 show that the phenol-based composite is the only material that passes the requirements of $\mathrm{THR}_{600 \mathrm{~s}}$ and FIGRA for class $\mathrm{B}$ (EN13501:2007). The $\mathrm{THR}_{600 \mathrm{~s}}$ values of all the investigated materials are well below the threshold of 7.5 MJ. However, the polyester-based, vinyl ester-based and epoxy-based GFRPs exceed the threshold criteria for FIGRA, which is $120 \mathrm{~W} / \mathrm{s}$. The polyester-based composite has the highest FIGRA, which is nearly three times higher than that of the epoxy-based composite. Although the total heat release $\mathrm{THR}_{600 \mathrm{~s}}$ of the four materials are around $4.7 \mathrm{MJ}$, the large variation in FIGRA values suggests that there are differences in the development of the flame across the samples. The high FIGRA index of the polyester-based composite indicates that the induced flame spreads fastest among the four types. The low FIGRA index of the phenol-based composite is the key property that helps this type of FRPC to pass the Eurocode. Figure 5 presents the snapshots of the burning process of the polyester-based composite panel at different times from the beginning to the end of the required duration for SBI test. At the $900^{\text {th }}$ seconds, the fire has not reached the edges of the panel, which indicate the composite material satisfy one of the important criteria of the class B of the EN13501-1:2007.

On the other hand, FIGRA values of the vinyl ester-based and epoxy-based composites are $12.5 \%$ and $1.8 \%$, respectively, which are higher than the threshold $120 \mathrm{MJ}$ of class B. It is suggested that increasing the proportion of fibre reinforcement can reduce this figure, as glass fibre has a threshold temperature of $880^{\circ} \mathrm{C}$ [23], thus it does not burn during the testing condition. It should be noted that this numerical analysis is conducted with the composite having a $30 \%$ weight of glass fibre reinforcement. The use of a higher percentage of fibre reinforcement should be investigated further.

The FIGRA of the polyester-based composite substantially exceeded the requirements according to EN13501:2007, and an even further increase in the proportion of glass fibre reinforcement could not provide sufficient reduction of FIGRA. It is, therefore, crucial to utilise flame retardants for polyester-based composites. While cost effectiveness drives the need to employ polyester-based composites, the addition of flame retardants and their influences on the manufacturing process and the strength of structures require further study in comparison with other composite systems.

\section{Conclusions}

FRPCs are innovative candidates to be used in modern façade systems because they can offer excellent performance and cost effectiveness in aesthetic and complex designs. Potential FRPC types for façade applications are considered in this paper. The major issue of FRPCs in façade systems is their poor fire performance, which is evaluated according to the Eurocode standards. A case study is carried out to investigate the fire performance of the materials in single burning item tests, which are full-scale fire test. Only phenol-based composites can pass the classification for class $\mathrm{B}$, which is the requirement for the materials to be used in building applications. However, phenol-based composites are difficult to be tailored owing to their complex curing process. In order to apply polyester-based and epoxy-based composites, further studies to improve their fire performance are necessary. The increase in glass fibre reinforcement portion and the utilisation of flame retardants are suggested for epoxy-based and polyester-based composites, respectively.

\section{Acknowledgements}

This work is conducted with the financial support of ARC Linkage Grant LP110100429. The authors would also like to acknowledge the support of Permasteelisa Pty Ltd with the experimental program.

\section{REFERENCES}

[1] Netravali, A.N. and S. Chabba, Composites get greener. Materials Today, 2003. 6(4): p. 22-29.

[2] Duflou, J.R., et al., Do fiber-reinforced polymer composites provide environmentally benign alternatives? A life-cycle-assessment-based study. MRS Bulletin, 2012. 37(4): p. $374-382$.

[3] Cristina, L., et al., Fire protection systems for reinforced concrete slabs strengthened with CFRP laminates. Construction and Building Materials, 2013. 47: p. 324-333.

[4] Zheng, Y., C. Li, and G. Yu, Investigation of structural behaviours of laterally restrained GFRP reinforced concrete slabs. Composites Part B: Engineering, 2012. 43(3): p. 1586-1597.

[5] Pan, Y., G. Yu, and Y. Zheng, Investigation of ultimate strengths of concrete bridge deck slabs reinforced with GFRP bars, in Construction and Building Materials. 2012. p. 482+.

[6] Li, X., H. Lv, and S. Zhou, Flexural behavior of GFRP-reinforced concrete encased steel composite beams. Construction and Building Materials, 2012. 28(1): p. 255-262.

[7] Blazewicz, S., J. Piekarczyk, and W. Piekarczyk, Compression strength of concrete cylinders reinforced with carbon fiber laminate, in Construction and Building Materials. 2011. p. 2365+.

[8] Ahmed, E.A., et al., Testing of full-scale concrete bridge deck slabs reinforced with fiber-reinforced polymer (FRP) bars, in Construction and Building Materials. 2011.p. 3956+.

[9] Al-Saidy, A.H., F.W. Klaiber, and T.J. Wipf, Strengthening of steel-concrete composite girders using carbon fiber reinforced polymer plates. Construction and Building Materials, 2007. 21(2): p. 295-302. 
[10] Mufti, A.A. FRPs and FOSs lead to innovation in Canadian civil engineering structures. 2003. Elsevier Ltd.

[11] Hollaway, L.C. The evolution of and the way forward for advanced polymer composites in the civil infrastructure. 2003. Elsevier Ltd.

[12] Bank, L.C., et al. A model specification for FRP composites for civil engineering structures. 2003. Elsevier Ltd.

[13] Uomoto, T., et al., Use of fiber reinforced polymer composites as reinforcing material for concrete. Journal of Materials in Civil Engineering, 2002. 14(3): p. 191-209.

[14] Campbell, F.C., Structural Composite Materials. 2010, Ohio: ASM International.

[15] NSAI, T.N.S.A.o.I., EN 13823:2010 Reaction to fire tests for building products - Building products excluding floorings exposed to the thermal attck by a single burning item. 2010.

[16] NSAI, T.N.S.A.o.I., EN 13501-1:2007 + A1:2009 Fire classification of construction products and building elements in Part 1: Classification using data from reaction to fire tests. 2009.

[17] Hjohlman, M., P. Andersson, and P. Hees, Flame Spread Modelling of Complex Textile Materials. Fire Technology,
2011. 47(1): p. 85-106.

[18] Andersson, J. and F. Persson, Computer supported simulation of pyrolysis. Diploma paper 01 - 08, Chalmers Lindholmen University College, Department of Chemical Engineering, 2001.

[19] Svenson, J., Thermal decomposition of biomass and construction materials : an experimental study / Jenny Svenson. 2004: 2004.

[20] Brown, J. and Z. Mathys, Reinforcement and matrix effects on the combustion properties of glass reinforced polymer composites. Composites part A - Applied Science and manufacturing, 1997. 28(7): p. 675-681.

[21] McCarthy, E.D., et al., Modelling flaming combustion in glass fibre-reinforced composite laminates. Journal of Composite Materials, 2013. 47(19): p. 2371-2384.

[22] Nair, C.P.R., Advances in addition-cure phenolic resins. Progress in Polymer Science, 2004. 29(5): p. 401-498.

[23] Faruqi, M., et al., Research and design guidelines for the construction of fiber-reinforced polymer reinforced concrete structures under fire exposure: A brief review. Journal of Reinforced Plastics and Composites, 2013. 32(17): p. 1302-1309 